\title{
Impact of the World-Wide Web on today's society - the economic and business sectors
}

\author{
L. van der Klashorst \\ Post Graduate Diploma in Information Management \\ Rand Afrikaans University \\ lizelleVK@nedcor.com
}

\author{
Contents \\ Introduction \\ Eelctronic workplace/commercial publishing/content on demand \\ Virtual enterprise and processes \\ Customer relationship management and collaborations technologies \\ Internet market spoilers/Web aggregators \\ Network and data security \\ Enterprise information portals and knowledge management \\ Digital/virtual currencies and payment systems \\ Trust and reputation \\ Intermediaries and cybermediaries \\ Discipline of informatics \\ Conclusion: the WWW in support of e-commerce \\ References
}

'There is nothing more important today for businesses - than innovation. What could be more important than to be able to reinvent yourself, to be more in touch with your environment, more aligned with your opportunities, more effective in using your talent so you can be constantly moving forward to create value' (Watters 2000: 70).

\section{Introduction}

The development and use of the WWW and resulting phenomena, for example e-commerce, are the most significant development of the 20th century and will also continue to be the most important driver of the 21st century. The Internet changed the business landscape by connecting companies, markets and individual consumers. By 2005, about 90 per cent of businesses around the world will be connected in business-to-business relationships, and about 25 per cent of global consumers will be connected through Web sites or through online communities that will enable like-minded consumers to share information and do business with a network of companies that offer goods and services (Ernst \&Young 2000). 
The reach of global e-commerce has grown with incredible speed and it will accelerate the zof business. The online business model will enable many companies to operate on a global scale as part of a connected economy. 'The connected economy is one [in] which businesses succeed by pursuing speed, connectivity, and value that is intangible and based on information and service' (Ernst \& Young 2000).

In the global e-commerce market business activities will take place 24 hours per day. Transactions will take place at any time, from any place, in real time. Real-time e-commerce capabilities require business processes and systems that are optimized for real-time customer support. The ability to think, build and operate rapidly is critical to business success (Ernst \& Young 2000).

To succeed in the connected economy businesses, companies should embrace the new rules of competition:

- Get connected electronically to suppliers and customers;

- speed up operations to function in real-time, by developing operational efficiency and flexibility - event driven;

- by rewarding employees, building and value intangible assets. Intangible assets are, for example, brand equity, customer relationships, the discovery, capture, and sharing of customer and market knowledge;

- develop short and long term alliances with partners with common interests. Move from the traditional linear supply chain and work across economic webs of common interests; and

- it is essential to exploit knowledge of customers and commercial alliances to develop 'offer' rather than discrete products or services (Ernst \& Young 2000).

'The rate of change in society is also accelerating as e-commerce and Internet connectivity reaches more people. We are living in a period of great social upheaval in which many traditional perspectives are neither consistent nor predictable. In a society this disrupted, many consumers and businesses are wary or even cynical. Businesses operating online must meet customers' needs by establishing a clear value proposition, and by executing it with consistency and dependability. Irrespective of whether the customer experience is physical or virtual, the experience always needs to be relevant to the customer. It is then possible for the business to become a trusted agent or partner - a centre of trust within the confusing and paid-paced e-commerce landscape. The ability to operate dependably and with consistent, relevant customer experience is becoming a powerful differentiator in the market' (Ernst \& Young 2000).

The above quoted paragraph emphasizes quite a few aspects/trends regarding e-commerce and the vehicle, namely the WWW, and the impact/significance thereof for business to survive and maintain a competitive edge in today's connected economy. The WWW creates the infrastructure that enables an online connected economy and resultant e-commerce. The above-mentioned aspects will be further exploited in this article.

\section{Electronic workplace/commercial publishing/content on demand}

Commercial publishing refers to a market and industry that comprise both end-user enterprises and associated vendors who create or license and distribute original documents or amalgamations of documents on a regular basis and as a primary revenue source (Abrams 18 August 1997). 
Internet commercial publication is an assembly of documents built around a common editorial theme (business, consumer interest, regional information) and produced by an enterprise or organization for profit. It does not exist in physical, but exists as user download of information from a Web site, has unlimited potential readership and has potential for substantial multimedia capacity. Internet subscription sales sites are: Wall Street Journal, Financial Times, Slate, Business Week and The Economist. Technology-enabled content can be seen on publication sites such as CNN and ABC News, which offer custom delivery based on past usage patterns, and Web-only sites such as AutoFinder and Inforspace that use technology to add value to basic content or advertising (Abrams 7 April 1998).

Developments in publishing technology are creating a revolution as great as that caused by Gutenberg's movable type press. At first publishers of printed magazines and newspapers viewed the hype surrounding 'the new Internet age' with a great deal of suspicion. Although many large publishers have Web sites, no substantial profits have been reported. Commercial Internet publishing efforts are primary undertaken as long-term investments and safeguard for industry and investor 'digital mind share' (Abrams 18 August 1997).

Expansion via the Internet represents the only viable long-term strategy for traditional publishers. The demand for printed newspapers and magazines will decline, but Internet publishing is positioned for exponential revenue growth through 2001 and onwards (Abrams 18 August 1997).

The exponential growth of the Internet is due to the compound effect of increases in Internet user numbers, content quality, commercial viability, technological improvements and network infrastructure. Internet revenue will increase even if user numbers remain constant, since improvements in Internet technologies and content will facilitate utilization (Abrams 18 August 1997).

Technological factors contributing to increased revenue are: push delivery/technology, embedded browsers, faster modems, advanced Internet publishing formats enabled by html and xml, and alternative delivery formats (Abrams 18 August 1997).

Commercial publishers and associated vendors will have to take into account the ongoing digital transformation in the industry in order to prevent declining market shares.

Interactive television was seen as key Internet application, but could not be effectively deployed until the Internet itself is established in terms of infrastructure, connected client devices and content availability. Internet television will not realize 'critical mass' in terms of profit generation potential until well after the year 2000. At least 40 per cent penetration of a population of consumers with high disposable income levels are necessary before investments in Internet broadcast and content delivery can earn profits for providers (Abrams 26 January1998).

Internet television adds a virtual leg to Internet usage limited to PC access. Televisionenabled Internet access, with uncomplicated operating systems under development, opens a vast new market for consumers who will not operate PCs. No one device has transformed consumer entertainment, information access and social patterns in the past 50 years, as has television (Abrams 26 January1998).

By 2003 the Internet-enabled networked information era will occur, when the majority of the world's information is created, stored, revised, published and archived digitally, and will be available instantaneously through electronic transmission. Equivalent exponential growth will occur in host devices, usage, commercial transactions, publishing, etc. (Abrams 26 January1998). 
Internet television content will not be textual, but will be primarily multimedia in nature, relying more on photo realism, and will take full advantage of high definition television formats and digital broadcasting technologies (Abrams 26 January1998).

By 2002 three major trends for Internet commercial publications can be expected:

- Textual-driven personal productivity;

- textual-driven business;

- multimedia consumer content accessed through both PCs and Internet television.

Developments in publishing technologies (xml) and content availability through 2002 will result in greatly increased utilization of the Web (Abrams 7 April 1998).

Metadata are data about data and are facilitated by xml. In commercial publishing, metadata provide information not explicitly present in a textual or visual document, but necessary for storage and processing by attribute type. Commercial publishers who expand to the Internet will fail in marketing content on a peruse basis unless end-users can retrieve information from publication repositories according to key attribute types. Organizing content by metadata can enable information retrievals through reference based on common knowledge. Wide commercial publishing acceptance of metadata descriptions will occur approximately by 2001, when the metadata-enabled 'intelligent document' will be available for textual document construction (Abrams 23 January 1998).

Content on demand is a rapidly emerging revenue source for commercial publishers. Internet publishing will not simply be restricted to 'pay-per-view' of sites; colour on-demand printing of complete publication issues will be enabled through networked installations of mass market colour printers (Abrams 23 January 1998).

Publishers of print-based newspapers and magazines must expand to Web delivery to ensure revenue growth, to increase market and investor valuations and to block new media entrants form attaining 'mind share', which must be purchased at a greater price once a market has been established. The Internet is posing a threat to print-based newspaper publishers in markets where Internet 'critical mass' has been reached, and is now beginning to pose a threat to business periodicals and consumer magazines.

Traditional commercial publishers should develop strategy for Internet expansion as entrants compete for shifting marketing revenue (Abrams 14 July 1999).

\section{Virtual enterprise and processes}

Enterprises will experience dramatic pressures in the next five years to change the way they operate, and this will require equally dramatic changes in external integration strategies with their trading partners. In the emerging virtual world, the ability to plug in and link new business partners, suppliers, customers and business processes dynamically will be critical to maintaining global competitiveness (Enslow 1999).

Enterprises that can rapidly configure to new business models based on changing market dynamics will have a distinct advantage over enterprises lacking the technical and business process wherewithal to alter models on the 'fly'. Electronic marketplaces, auctions, Internetbased dynamic trading-partner communities, dynamic trading environments and supply chain portals will support this model (Enslow 1999). 


\section{Customer relationship management and collaborations technologies}

Customer relationship management is the activity by which a customer service, sales or marketing organization analyses and appreciates the long-term value of each individual customer, and then gears sales and service activities to be appropriate for that customer (Fluss 1999).

Collaboration can take many forms, but generally involves a real-time connection with a customer, either by an agent taking control of the Web page, while speaking on the telephone with one or several customers at multiple locations and leading them through the event, or by sharing documents and applications on the Web that originated either from the organization or the customer. Conferencing and seminars are also useful collaborative offerings (Amuso and Moaz 1999).

Why is collaboration necessary? Friction between consumers and sellers on the Web in the form of user unease with completing forms or frustration with locating answers to questions regarding product or services lowers the tendency to buy by an average of approximately 80 per cent. Collaboration that offers live assistance to the user, together with delivery of dynamic Web content helps foster customer intimacy (Amuso and Moaz 1999).

Owing to product immaturity, non-viable vendors and lack of integration with front-office applications, enterprises should be wary of these tools until both the market and the technologies are mature (Amuso and Moaz 1999).

Microsoft's NetMeeting is becoming widely used for extranet collaboration. It supports audio, video, white boarding, chat and application sharing. Data privacy, data integrity, authentication and authorization characteristics must be individually considered for each NetMeeting service, because multiple data connections are established between NetMeeting clients (Zboray 1999).

\section{Internet market spoilers/Web aggregators}

What is an internet market spoiler? It is a Web-based business that aggregates information about a market and its suppliers and provide the aggregated information to consumers on a Web site. Market spoilers are offering decision-support applications that integrate supplier information with third-party information and with user requirements and preferences. It allows customers to differentiate between services and features offered by the various competitors rather than relying solely on the supplier's reputation or brand (Barnick and Meehan 1999).

Transaction-linked market spoilers can assist directly in the selling process in some areas. When the transaction can be tracked back to the market spoiler, the spoiler and the supplier share in the revenue (Barnick and Meehan 1999).

An indirect market spoiler sells advertising and related products and services, but is not directly tied to the sale (Barnick 1999).

'Bot' technology automatically searches competitive Web sites or databases to compare prices. The results of the search are delivered back and organized for side-to-side comparison (Barnick and Meehan 1999). 
Market spoilers are also logical Internet market-makers, operating auctions or bid-ask systems, which allow purchasers to request bids for complex goods and services and suppliers to provide quotes, expedited through the market-maker's communications and information services (Barnick and Meehan 1999).

Enterprises will have to plan for the impact of emerging Internet market spoilers to prevent a negative impact in both their core and Internet businesses. Users are increasingly going to the Web for information and support in making purchasing decisions. They therefore make use of Web aggregator services that answer their questions and help them with decisions in a neutral fashion (Barnick and Meehan 1999).

\section{Network and data security}

Enterprises must take measure to secure corporate and multi-enterprise Internets. Internet enterprises are vulnerable to DoS, as these attacks exploit weaknesses in the TCP/IP protocol used on the Internet. The degree of risk is proportionate to the degree of revenue dependent on the Web (Pescatore and Malik 2000).

What is a DoS attack? It typically floods the target with Internet traffic, often appearing to be legitimate Web site access requests. The attacker first breaks into multiple Internet sites and installs relay software. Each infected site can then be controlled remotely by the attacker and used to launch DoS attacks (Pescatore and Malik 2000).

Enterprises can implement limited throttling controls on firewalls, load balancers and edge routers, but these controls will provide limited protection while impacting some legitimate users. Internet Service providers need to provide network controls and reject spoofed IP addresses at the source of the attack (Pescatore and Malik 2000).

According to GartnerGroup Interactive there are three types of Internet business models:

- Dot-com: a pure virtual company that has outsourced all traditional infrastructure or delivers digital products only;

- hybrid business: a brick-and-mortar business that has responded to the Internet threads by creating

- Web front end with links to back-end systems, or a dot-com that is creating traditional infrastructure to meet customer expectations; and

- brick and mortar: a traditional company with on-Web channels as the sales outlet for its products and services.

Pure dot-com companies are the most at risk from 'denial of service' attacks, as their entire revenue stream may be interrupted. Hybrid companies face a lesser degree of revenue exposure to Internet interruptions. Brick-and-mortar companies may have little to no direct revenue exposure to DoS attack. Effective protection against DoS attacks rests in the hands of the Internet service providers providing the physical connection. E-businesses should demand quality-of-service statements from their ISPs requiring them to control a DoS attack (Pescatore and Malik 2000).

When making use of collaborative technologies, attention should be given to special security measures as a result of data and information sharing. 


\section{Enterprise information portals and knowledge management}

Internet portals provide a window into the information of the Internet, while enterprise portals provide a similar window into the information, systems and processes of an enterprise and are facilitated through Web editing tools (Phifer 1999).

Enterprise portals typically refer to services aimed at employee productivity. There are many types of enterprise portals: internally facing, customer facing and trading-partner facing. An internal facing portal provides access to employees and contractors of an enterprise. Customer facing portals provide access not only to relevant information but also to ecommerce applications. Trading-partner facing portals facilitate supply chain management. Some enterprise portal vendors only target one specific face. Enterprises should assure that any potential vendor supports the desired and also has the flexibility to support other faces, as business needs change (Phifer 1999).

Capabilities of enterprise portals should be:

- Index and search capabilities: multiple data repositories, structured and unstructured data, and internal and external data;

- Structured data (data warehouses, data marts, application databases);

- Unstructured data (office documents, Web documents) related to document management, knowledge management, Web publishing and content management disciplines.

- Taxonomy: Aggregation of information, creation of taxonomy, BI functionality and personalization all depend on a common language defining data attributes. High levels of portal functionality require a metadata repository, or dictionary. In the absence of a dictionary, items will be categorized incorrectly or under multiple identities, reducing the effectiveness of searching and personalization.

- Application integration: Integration of the different applications used for different processes are crucial.

- Security/permissioning: Multiple security models are typically represented in the information repositories that a portal must deal with' delivering comprehensive security for aggregated internal and external content will be a significant technology challenge for vendor and enterprises.

- Personalization (Phifer 1999).

Enterprises evaluating technology for knowledge management, will recognize the overlaps with enterprise portals. Current technologies for knowledge management and enterprise portals share the same parentage, namely the Internet and its, indexing, search and retrieval of data from disparate sources (Harris 1999).

Management of the information overload and avoiding productivity loss are growing concerns for enterprises. Knowledge management and enterprise portal technology help enterprises to maintain productivity and close information gaps (Harris et al. 1999).

The aim of Knowledge management is to manage information in the unique context of the enterprise. Context is embedded in the enterprise's business values, strategic direction and experiences, and in the insight and expertise of employees. Such contextual application of knowledge is hard to duplicate and thus is the source of sustainable competitive advantage in mature knowledge management (Harris et al. 1999).

Knowledge management technology is augmented with human infrastructure to filter content to align with business and knowledge management strategic direction, to index and link resources (people, processes and content) to the taxonomy, and to maintain profiles and 
alignment of communities. These activities add context to knowledge resources, reduce extraneous information and improve the fit of content to user needs (Harris et al. 1999).

Although there is a significant overlap between enterprise portal and knowledge management technology, implementing an enterprise portal is not knowledge management. Enterprises cannot achieve the implementation of a knowledge management discipline with technology alone (Harris et al. 1999).

\section{Digital/virtual currencies and payment systems}

Taking the rapid growth of e-commerce and the Internet as vehicle into consideration, the creation of a secure cost-effective payment system, which will be able to support growing commercial activities, is crucial. Electronic payment systems for large amounts have been in operation for some time, but a cost-effective and efficient electronic payment system is needed for making low value payments (Crede).

An electronic payment system will influence institutional and legal structures and will provide opportunities for the creation of completely new sets of global and national trading relationships (Crede).

As a result of the growth of the Internet, and e-commerce, there is increasing pressure to move from existing paper-based payment systems to electronic transfer. Serious efforts to establish a secure and cost effective 'mass' market electronic system are in progress, but far from mature (Crede).

The latest development regarding digital currency and cash-like payment systems, is iPIN (Davis 2000).

\section{Trust and reputation}

'Relative to information security and electronic commerce, trust is a necessary component. Trust itself represents an evaluation of information, on analysis that requires decisions about the value of specific information in terms of several factors' (Reagle).

The most popular domain for the usage of the term 'trust' has been research regarding authentication, and the infrastructure for public key technology in a networked environment. Technology strives to accommodate trust and authenticity through developments e.g. protocols, digital signatures and contracts, encryption techniques and technology, etc. (Reagle).

How will trust be decided on the Internet? Trust is simply information; whether it is information of poor quality, or improperly used information. Information is employed to make decisions and assign trust. 'Cryptographers, economists, policy makers and participants in the global financial markets are slowly building methods to take advantage of the vast quantity of electronic information' (Reagle). 
The prediction was that, because of the ubiquitous information infrastructures on the Web, intermediaries would be bypassed in electronic markets. On the contrary, it is likely that widely available information infrastructure will reinforce the position of the traditional intermediaries, and networks will promote the growth of a new generation intermediaries, namely 'cybermediaries'. Cybermediaries are organizations that perform the mediating tasks in the world of electronic commerce to address the new needs imposed on producers and consumers by electronic commerce (Sarkar et al.).

Intermediary functions that benefit consumers include assistance in search and evaluation, needs assessment and product matching, risk reduction, and product distribution/delivery. Intermediary functions that benefit producers are creating and disseminating product information and creating product awareness, influencing consumer purchases, providing customer information, reducing exposure to risk and reducing cost of distribution through transaction scale economies (Sarkar et al.).

\section{Discipline of informatics}

Social informatics is 'the interdisciplinary study of the design, uses and consequences of information technologies that takes into account their interaction with institutional and cultural contexts' Kling). The study of the impact of the WWW on the economic society and e-commerce, in particular, can be a subdivision of the impact of technology on society as a whole.

\section{Conclusion: the WWW in support of e-commerce}

The Internet as a massive global network and, the tremendous development of the WWW in particular, has led to a critical mass of consumers and firms participating in a global on-line marketplace. The popularity of the WWW as commercial medium is due to its ability to facilitate global sharing of information and resources, and its potential to provide an efficient channel for advertising, marketing and even direct distribution of certain goods and information services (Hoffman).

The WWW has the potential to change the way firms do business with their customers by blending publishing, real-time communication broadcast and narrowcast. The Web supports:

- Discussion groups;

- multiplayer games and communication systems;

- file transfer and remote login;

- electronic mail;

- global information access and retrieval system (Hoffman).

The most significant developments with regard to a business and marketing perspective are:

- Destination sites, e.g. online storefronts, Internet presence sites and content sites; and

- Web traffic control sites, with the purpose of directing consumers to various destination sites, e.g. malls, incentive sites, and search agents (Hoffman).

The Web as commercial medium offers the following benefits:

- Consumer benefits: Buyer benefits arise from the structural characteristics of the 
medium and include availability of information, provision of search mechanisms, and an on-line product trial, all of which can lead to reduced uncertainty in the decisionmaking process of what to purchase; and

- benefits to the firm: the Web as distribution channel for marketing communications and the interactive nature of the medium (Hoffman).

Barriers to commercialization of the Web are:

- Ease of access. Convenience is at the core of adoption. In the context of the Web, ease of access includes high-speed access (bandwidth), ease of finding a service provider and to have the computer infrastructure available at home; and

- secondary barriers are ease of use, price and risk, such as privacy and security. Software must be user-friendly and easy to install (Hoffman).

\section{References}

- Abrams, C. 18 August 1997. Commercial publishing key issues 1997-1998. Gartner Interactive. Research Note:1-4.

- Abrams, C. 14 July 1999. Commercial publications: Web migration time frames. Gartner Interactive. Research Note: 1-4.

- Abrams, C. 23 January 1998. Metadata descriptions: key to Internet-age profitability. Gartner Interactive. Research Note: 1-4.

- Abrams, C. 26 January 1998. Internet television: prime time for commercial publishers. Gartner Interactive. Research Note: 1-4.

- Abrams, C. 7 April 1998. Trends in commercial publishing: Internet publications. Gartner Interactive. Research Note: 1-4.

- Amuso, C. and Moaz, M. 1999. Reaching the customer with Web collaboration technology. Gartner Interactive. Research Note: 1-5.

- Barnick, D. and Meehan, P. 1999. Internet market spoilers: the consumer takes command. Gartner Interactive. Research Note: 1-4.

- Crede, Andreas. Electronic commerce and the banking industry: the requirement and opportunities for new payment systems using the Internet. [Online]. Available WWW: http://ascusc.org/jcmc/vol1/issue3/crede.html.

- Davis, Jeffrey. 2000. Spare change agents. Intelligence 6(3):84-94.

- Enslow, B. 1999. Strategies for supporting the virtual enterprise and beyond. Gartner Interactive. Research Note: 1-5.

- Ernst \& Young. 2000. Web visions: e-commerce. Intelligence 6(3).

- Fluss, D. 1999. Marketing e-business, e-transformation and e-CRM. Gartner Interactive. Research Note: 1-3.

- Harris, K. et al. 1999. The enterprise portal ; is it knowledge management? Gartner Interactive. Research Note: 1-5.

- Hoffman, Donna L. et al. Commercial scenarios for the Web: opportunities and challenges. [Online]. Available WWW: http://www.ascusc.org/jcmc/vol1/issue3/hoffman.html.

- Kling, Rob. What is social informatics and why does it matter? [Online]. Available WWW: http://www.dlib.org/dlib/january99/kling/01kling.html.

- Pescatore, J and Malik, W. 2000. E-business survival during denial of service tornadoes. Gartner Interactive. Research Note: 1-4.

- Phifer, G. 1999. Enterprise portal trends emerge among confusion. Gartner Interactive. Research Note. p.1-3.

- Reagle, joseph M. Trust in electronic markets: the convergence of cryptographers and economists. [Online]. Available 
WWW: http://www.firstmonday.dk/issues/issu2/markets/index.html.

- Sarkar, Mitra B. et al. Intermediaries and cybermediaries: a continuing role for mediating players in the electronic marketplace. [Online]. Available WWW: http://www, ascusc.org/jcmc/vol1/issue3/sarkar.html.

- Watters, Ethan. 2000. Kao's Theory. Intelligence 6(3):65-72.

- Zboray, M. 1999. NetMeeting: is it secure enough for extranet collaboration? Gartner Interactive. Research Note: 1-5.

\section{Disclaimer}

Articles published in SAJIM are the opinions of the authors and do not necessarily reflect the opinion of the Editor, Board, Publisher, Webmaster or the Rand Afrikaans University. The user hereby waives any claim he/she/they may have or acquire against the publisher, its suppliers, licensees and sub licensees and indemnifies all said persons from any claims, lawsuits, proceedings, costs, special, incidental, consequential or indirect damages, including damages for loss of profits, loss of business or downtime arising out of or relating to the user's use of the Website. 
ISSN 1560-683

Published by InterWord Communications for the Centre for Research in Web-based Applications, Rand Afrikaans University 